\title{
Reflexões Sobre a Pesquisa Qualitativa Aplicada ao Turismo ${ }^{1}$
}

\author{
Reflections on the Qualitative Research Applied to Tourism
}

\author{
Reflexiones sobre la Investigación Cualitativa Aplicada al Turismo
}

Maria Lucia Bastos Alves ${ }^{2}$

\begin{abstract}
Resumo
Considerando que os métodos qualitativos têm por princípio o processo indutivo baseado na descoberta e na compreensão das ações humanas em suas diferentes perspectivas culturais, $o$ artigo tem como objetivo contribuir com reflexões de ordem metodológica no campo da pesquisa qualitativa com o intuito de mostrar como diferentes procedimentos metodológicos, com suas respectivas técnicas de investigação, possibilitam maiores aprofundamentos e novas sensibilidades para os estudos do turismo.
\end{abstract}

Palavras-chave: métodos qualitativos; técnicas; turismo.

\section{Abstract}

Whereas qualitative methods are in principle the inductive process based on the discovery and understanding of human actions in their different cultural perspectives, the article aims to contribute to reflections on methodological issues in the field of qualitative research in order to show how different procedures methodologies, with their investigative techniques, and new insights allow greater sensitivity for studies of tourism.

Keywords: qualitative methods; techniques; tourism.

\section{Resumen}

Mientras que los métodos cualitativos son, en principio, el proceso inductivo basado en el descubrimiento y la comprensión de las acciones humanas en sus diferentes perspectivas culturales, el artículo tiene como objetivo contribuir a la reflexión sobre cuestiones metodológicas en el campo de la investigación cualitativa con el fin de demostrar cómo

\footnotetext{
${ }^{1}$ Trabalho apresentado no I Seminário Internacional de Estudos Críticos em Turismo realizado nos dias 24 e 25 de março de 2011, organizado pelo grupo de pesquisa Estudos Críticos em Turismo - ESCRITUR/UFRN/CNPq. ${ }^{2}$ Doutora em Sociologia pela Universidade de São Paulo (USP), professora da Universidade Federal do Rio Grande do Norte (UFRN), lotada no Departamento de Ciências Sociais (DCS), Programa de Pós-Graduação em Ciências Sociais (PPGCS) e Programa de Pós-Graduação em Turismo (PPGTUR).
} 


\section{TURISMO EM ANÁLISE}

diferentes procedimientos metodologías, con sus técnicas de investigación y nuevos conocimientos permiten una mayor sensibilidad para los estudios de turismo.

Palabras clave: métodos cualitativos; las técnicas; el turismo.

\section{Introdução}

$\mathrm{O}$ artigo tem como objetivo apresentar reflexões no campo da pesquisa qualitativa com o intuito de mostrar como diferentes procedimentos metodológicos e suas respectivas técnicas de investigação possibilitam maiores aprofundamentos e novas sensibilidades para os estudos do turismo. Considerando que os métodos qualitativos têm por princípio o processo indutivo, baseado na descoberta e na compreensão das ações humanas em suas diferentes perspectivas culturais, evidenciam-se as técnicas mais familiares pertencentes a essa abordagem em que a análise dos significados e das práticas cotidianas mostra-se tão essencial quanto as narrativas e os discursos dos sujeitos pesquisados.

A escolha do método qualitativo tem como justificativa o reconhecimento de que o conhecimento é uma construção coletiva que parte da realidade dos sujeitos, mediados por processos de reflexão e desvelamento da realidade estudada. Momento em que pesquisador e pesquisados interagem de forma criativa. Conforme Thiollent (1987, p. 132), "mais do que informações ocasionais, certos indivíduos ou grupos implicados numa determinada situação devem se tornar, no decurso da pesquisa, investigadores nesta situação.”

Ciente de que a escolha e a aplicação dos métodos encontram-se vinculadas ao posicionamento epistemológico e tratamento dos dados, ressalta-se que não se pretende discutir questões de ordem epistemológica que remetem à teoria do conhecimento, tampouco as divergências e complementaridades entre os métodos quantitativos versus qualitativos. Mas apresentar algumas técnicas de investigação referentes às pesquisas qualitativas que concorrem para dar conta dessa complexa tarefa. E, como toda pesquisa é precedida e acompanhada por uma série de implicações teóricas, tanto no âmbito do pesquisador, do fenômeno estudado, quanto da própria estrutura do campo de conhecimento, a aplicação das diferentes técnicas e instrumentos de pesquisas qualitativas requer um melhor tratamento 


\section{TURISMO EM ANÁLISE}

teórico antes e depois da coleta de dados. Como afirma Bourdieu (1999, p. 48), por mais parcial que seja um objeto de pesquisa, ele só pode ser definido e construído em função de uma problemática que permita submeter a uma interrogação sistemática os aspectos da realidade colocados em relação entre si pela questão que lhes é formulada. Por isso, insiste na "vigilância epistemológica", atitude de cuidado permanente com as condições e os limites da validade de técnicas e conceitos. Deve-se repensar cada operação da pesquisa, mesmo a mais rotineira e óbvia, a fim de proceder à crítica dos princípios e à análise das hipóteses para determinar a sua origem lógica (BOURDIEU, 1999, p. 14).

\section{O Método: um breve olhar}

Muito se tem discutido sobre a metodologia e seu papel nas investigações acadêmicas. É sabido que desde o final do século XVII a palavra ciência, no sentido moderno, tornou-se progressivamente critério de verdade. A partir daí, o conhecimento científico vai se delineando conforme o estatuto metodológico que fixa as fronteiras entre as diferentes formas de conhecer a realidade. Demarcando seus pressupostos lógicos e metodológicos, a razão científica é metódica e obedece a uma lógica construída segundo categorias matemáticas. Isto é, o conhecimento científico deve seguir um caminho fundado na experiência com o objetivo de conhecer as leis que o regem.

$\mathrm{Na}$ medida em que, as ciências históricas e sociais se apresentavam como um tipo de conhecimento heterogêneo em relação ao das ciências da natureza, surgia a necessidade de definir a sua especificidade e determinar as condições sob as quais se poderia reconhecer validade do seu conhecimento. Diferentes formas de procedimentos metodológicos são colocadas no processo de construção. Encontra-se, nessa discussão, o método dedutivo proposto pelos racionalistas René Descartes, Baruch Spinoza e Wilhelm Leibniz; o método indutivo defendido pelos empiristas Francis Bacon, Thomas Hobbes, John Locke e David Hume $^{3}$; o método hipotético-dedutivo proposto por Karl Popper; o método dialético fundamentado na dialética proposta por Friedrich Hegel; o materialismo histórico dialético

\footnotetext{
${ }^{3}$ Berkeley G. Tratado sobre os princípios do conhecimento humano. In: Coleção Os Pensadores. São Paulo: Nova Cultural; 1992.
} 


\section{TURISMO EM ANÁLISE}

proposto por Karl Marx e o método fenomenológico, preconizado por Edmund Husserl segundo o qual o sujeito da pesquisa é de grande importância no processo de construção do conhecimento (GIL,1999; LAKATOS \& MARCONI 1993; TRIVIÑOS, 1992).

Alicerçada no nascimento da sociedade técnico-industrial e sob o amparo da ciência da natureza, encontra-se a abordagem teórico-metodológica positivista, com origens na tradição empirista inglesa (F. Bacon; D. Hume, Stuart Mill, Herbert Spencer) e francesa (Condorcet, Saint Simon). Na sociologia, esta linha de pensamento é representada por Augusto Comte (1798-1857) e Émile Durkheim (1858-1917). Este último, por ser o primeiro a sistematizar exclusivamente uma obra metodológica, com vistas à elaboração de uma "teoria da investigação sociológica", defende o modelo de sociedade fundamentada nas ciências biológicas e naturais, devendo os fatos sociais ser estudados de forma neutra e objetiva. O que se pode constatar na primeira é a mais fundamental das regras relativas à observação dos fatos, em que o autor insiste em considerar os fatos sociais como coisas. O que quer dizer: “considerar os fenômenos sociais em si mesmos, destacados dos indivíduos conscientes, que formulam representações a seu respeito: é necessário estudá-los de fora, como coisas exteriores, pois é nesta qualidade que se apresentam a nós" (DURKHEIM, 1977, p. 24).

Conceitos como função, adaptação, integração, consenso, entre outros evidenciam os princípios básicos da abordagem durkheimiana, pautada no modelo organicista das ciências biológicas e aponta para a necessidade de estudar as instituições sociais numa perspectiva evolutiva. Tais características se materializam na dimensão integradora e adaptativa das instituições e falam uma linguagem institucional, que explica como as instituições se mantêm (DEMO, 1983, p. 46).

Vista como uma das vertentes do positivismo, a abordagem funcionalista terá expressividade na antropologia inglesa, com Malinoswki (1884 - 1942) e Raddclife-Brawn (1881-1955), e na sociologia americana de Merton (1919-2003) e Parsons (1902-1979). Tal perspectiva difere do positivismo clássico, na medida em que nega as leis gerais que regem o funcionamento da sociedade como um todo, sendo aplicável à compreensão da estrutura social e da diversidade cultural. 


\section{TURISMO EM ANÁLISE}

Contrário a esta corrente e adeptos da distinção entre ciências humanas e ciências naturais, encontram-se os alemães vinculados ao idealismo dos filósofos a exemplo de F. Hegel (17701831) e Schleiermacher (1768-1834), Kant (1724-1804) e os neokantianos Wilhelm Windelband (1848-1915), Heinrich Rickert (1863-1936) e Wilhelm Dilthey (1833-1911). Este, distinguindo explicação (erklären) da compreensão (verstehen) evidenciava o modo explicativo característico das ciências naturais, procurava o relacionamento causal entre os fenômenos, enquanto a compreensão seria o modo típico de proceder das ciências humanas, que visa ao conhecimento da experiência humana e procura extrair dela seu sentido ou significados. Na sociologia, destacam-se os estudos de Max Weber (1864-1920) e o método compreensivo, que concebe a realidade empírica como infinita, sendo necessário efetuar os estudos por uma interpretação, baseada em comparações, análises avaliativas e referência a valores. Privilegia o sentido e a atividade dos sujeitos que interagem em função dos significados atribuídos às ações sociais.

Para Weber, os fenômenos culturais deviam ser conhecidos tanto em seus aspectos racionais como irracionais. Entretanto, consciente das limitações do homem, considerava que um conhecimento generalizador dos fenômenos culturais excedia as pretensões de uma ciência. Esta devia limitar-se a entender e a compreender, por um lado, a importância cultural dos acontecimentos singulares (em relação aos valores) e, por outro, as causas pelas quais foram produzidos historicamente desta maneira e não de outra. A significação cultural ocorre em função de sua relação com sistema de determinados valores que, por sua, vez encontra-se em permanente conflito com outros.

Com o intuito de construir uma análise dos fenômenos no plano técnico do método, Weber enfatiza que o pressuposto de validade do conhecimento científico dependerá da objetividade dos métodos empregados, no sentido de que a estrutura lógica dos mesmos possa garantir a transmissão da verdade dos enunciados observacionais às hipóteses e vice-versa, com vistas à verificação empírica dos resultados. Para tanto, propõe a utilização do tipo ideal, visto como um recurso metodológico pelo qual os fenômenos socioculturais podem ser medidos ou comparados, em termos da eficácia dos conhecimentos adquiridos em torno das relações sociais, das condições causais e da significação. 


\section{TURISMO EM ANÁLISE}

Outra perspectiva metodológica das ciências sociais encontra-se no pensamento marxista: é o Materialismo Histórico Dialético, formulado por K. Marx ao longo de suas obras ${ }^{4}$. Influenciado pela filosofia clássica alemã de Hegel (1770 - 1831) - idealismo histórico - e Fuerbach (1804 - 1872) - materialismo a-histórico; pela economia Política Inglesa (Smith e Ricardo) e pelo Socialismo Utópico (Fourier, Saint Simon, Proudhon), o método dialético crítico, ou materialismo histórico dialético, proposto por Marx, auxilia no desvendamento do fenômeno social, a partir de uma análise que parte da estrutura e busca, na história, sua gênese, contemplando a articulação dos múltiplos fatores sociais. Em termos operacionais, todo e qualquer objeto de estudo é real e efetivamente aparece como objeto humano, social e histórico. Portanto, o processo de conhecimento do objeto não ocorre de modo direto, imediato ou espontâneo, mas articulados num todo, que só existe como produto de uma atividade específica e teórica. Marx denomina esses objetos, respectivamente, de "concreto pensado" e "concreto real". O primeiro existe no pensamento, no terreno da abstração, na medida em que é produzido teoricamente, enquanto que o segundo existe real e efetivamente, independente do que seja pensado, ou seja, construído teoricamente - ou não. Processo definido como "síntese de múltiplas determinações" cujo objetivo é captar os nexos internos, superar o nível das aparências e chegar a essência, destruindo o mundo das aparências, ou seja, da "pseudo-concreticidade" (KOSIK, 1976). Portanto, o Materialismo Dialético apresenta-se não apenas como estudo da produção material, mas como produção da existência social como um todo e como resultado de todas as manifestações culturais, religiosas, políticas e ideológicas.

O pressuposto fundamental dessa abordagem introduz o princípio da contradição como algo permanente que explica a transformação. Nada se constrói fora da história, mas através de uma totalidade dinâmica de relações que explicam e são explicadas pelo modo de produção de cada época. A reconstituição histórica é fundamental para desvendar as expressões da questão social materializadas na vida de sujeitos, grupos e instituições sociais efetivadas no detour, movimento regressivo (que vai ao passado) e progressivo (que retorna ao presente),

\footnotetext{
4 A Ideologia Alemã (1845-46); Manifesto do Partido Comunista (1848); Formações Econômicas Précapitalistas (1858); Prefácio de Contribuição à Crítica da Economia Política (1859); O Capital (1885 - 1894).
} 
desvendando as contradições desse percurso para, a partir da reflexão dialética (não só a crítica, mas a articulação de novas mediações) superar suas limitações (LEFEBRE, 1991).

É, portanto, neste cenário, no qual se enfatizam a intersubjetividade, os conflitos e contradições, as interações e os significados das práticas sociais, que o debate sobre a pertinência e cientificidade dos métodos qualitativos ganha força e notoriedade. Diferentes linhas de pensamento, cada qual caracterizada por um embasamento teórico específico em relação ao seu próprio programa metodológico possibilitará a construção dos pressupostos teórico-metodológicos das pesquisas qualitativas. Sejam eles: a) a sociologia compreensiva de Max Weber; b) os estudos antropológicos realizados no final de século XIX (Le Play; L. Morgan; Franz Boas e B. Malinowski) e início do século XX com Ruth Benedict e Margaret Mead; c) a Escola de Chicago com o interacionismo simbólico, de Georg H. Mead e John Dewey; d) a Etnometodologia de Goffman e Harold Garfinkel, que evidenciam o estudo empírico das práticas cotidianas e priorizam o conhecimento da vida social a partir dos significados e interpretações de diferentes pontos de vista, tanto do pesquisador quanto do pesquisado.

\section{A Pesquisa Qualitativa}

A pesquisa qualitativa tem por princípio as orientações filosóficas da fenomenologia e da dialética, com especificidade no estudo do comportamento humano e social, que se fundamenta na relação dinâmica entre o sujeito e o objeto. Valoriza a contradição do fato observado e a criatividade do pesquisador, cabendo-lhe descobrir o significado das ações e relações sociais.

Com pressupostos teóricos metodológicos multidisciplinares - sociologia, antropologia, ciência política, psicologia e filosofia - expressa diferentes linhas de pensamento na historia do conhecimento científico ${ }^{5}$, e ganha expressividade no início do século XX até a Segunda Guerra Mundial, com as pesquisas antropológicas de Malinowski e a Escola de Chicago, em

\footnotetext{
${ }^{5}$ Pesquisas como a de Le Play Les ouvriers européens (1920) e os estudos de Malinowski, Argonauts of the Western Pacific, (1922) e Sexual life of savage, (1929) que retratam a importância das técnicas da etnografia e observação participante tornaram-se referências nas pesquisas qualitativas.
} 


\section{TURISMO EM ANÁLISE}

sociologia. Durante este período, o interesse pelo outro, pelo diferente, a descrição e a interpretação dos fenômenos contribuíram para os avanços e as discussões ocorridas tanto nos Estados Unidos quanto na Alemanha ${ }^{6}$. Segundo Flick (2009, p. 29), três perspectivas resumem as pesquisas qualitativas, no que se refere aos pontos de referência teórica: primeiro, encontram-se as tradições do interacionismo simbólico e da fenomenologia. O segundo diz respeito às perspectivas teóricas da etnometodologia e do construcionismo, as quais se interessam pelas rotinas diárias e pela produção da realidade social. O terceiro ponto de referência abrange as posturas estruturalistas ou psicanalistas, que compreendem estruturas e mecanismos psicológicos inconscientes e configurações sociais latentes. Tais perspectivas diferenciam-se por seus objetos de pesquisas e pelos métodos que empregam. Assim, torna-se indispensável saber aplicar os instrumentos metodológicos que privilegiam o significado cuja função estruturante gira em torno do que as coisas significam para as pessoas e como elas se organizam e concebem os seus modos de vidas. Ou seja,

[...] aquelas capazes de incorporar a questão do significado e da intencionalidade como inerentes aos atos, às relações, e às estruturas sociais, sendo essas últimas tomadas tanto no seu advento quanto na sua transformação, como construções humanas significativas. (MINAYO, 1996, p. 10).

Uma gama de técnicas se coloca disponíveis para a coleta e análises dos dados. Sejam elas: a observação participante, o uso de entrevistas semiestruturadas ou narrativas; estudos de caso; as histórias de vida; as análises de conteúdo de documentos; os grupos de discussão ou grupos focais; a etnografia; o diário de campo em que deve conter as observações e reflexões sobre expressões verbais e ações dos sujeitos, descrevendo-as primeiro e, depois, fazendo comentários críticos, além de observações e reflexões sobre a atuação dos próprios pesquisadores.

A observação participante, realizada através do contato direto do pesquisador com o fenômeno observado para obter informações sobre a realidade dos atores sociais em seus

\footnotetext{
${ }^{6}$ Consultar FLICK, Uwe. Introdução à pesquisa qualitativa. 3. Ed. Porto Alegre: Artmed, 2009.
} 


\section{TURISMO EM ANÁLISE}

próprios contextos, tem se tornado uma técnica imprescindível nos estudos do turismo. Possibilita o pesquisador captar uma variedade de situações ou fenômenos que não são obtidos por meio de perguntas. Ao estabelecer uma relação face a face com os observados, o observador pode modificar e ser modificado pelo contexto. A importância dessa técnica reside no fato de podermos captar uma variedade de situações ou fenômenos que não são obtidos por meio de perguntas, uma vez que, observados diretamente na própria realidade, transmitem o que há de mais importante e evasivo na vida real (MINAYO, 1994). Torna-se importante para a comprovação de dados, para o complemento de outros, obtidos durante as entrevistas formais e, muito mais ainda, para obter dados ainda não citados durante as mesmas. As fotografias e filmagens e gravações são recursos de registros utilizados, pois ampliam o conhecimento do estudo e proporcionam documentar momentos ou situações que ilustram o cotidiano vivenciado.

No caso do uso das entrevistas, Taylor e Bogdan (1992) evidenciam que é difícil determinar quantas pessoas se devem entrevistar em um estudo qualitativo. É preciso considerar diversos fatores, como a qualidade e a potencialidade demonstradas pelas pessoas a serem entrevistadas, a natureza do objeto de estudo, tendo como guia o marco teórico que ajuda o investigador no desenvolvimento das compreensões teóricas sobre a área estudada da vida social. Os autores enfatizam que o marco principal da entrevista em profundidade é a aprendizagem

sobre o que es importante en la mente de los informantes: sus significados, perspectivas y definiciones; el modo en que ellos ven, clasifican y experimentan el mundo. (...) El entrevistador cualitativo debe hallar modos de conseguir que la gente comience a hablar sobre sus perspectivas y experiencias sin estructurar la conversación ni definir lo que aquélla debe hablar. A diferencia del observador participante, no puede quedarse a tras e esperar que las personas hagan algo antes de formular preguntas (TAYLOR \& BOGDAN, 1992 p. 115).

A história de vida utilizada por antropólogos e sociólogos, desde o final do século XIX até a década de 1950, teve suas ressalvas no que diz respeito às dificuldades apresentadas em virtude de mostrar apenas um aspecto parcial da realidade, devendo ser complementada com 


\section{TURISMO EM ANÁLISE}

outras técnicas. O desenvolvimento das técnicas estatísticas, nos finais dos anos 1940, relegou para um segundo plano esta técnica por considerá-la ligada à influência da psique individual. Em seu lugar, utilizou-se a técnica do questionário que parecia mais objetiva para obterem os dados. Entretanto, aos poucos, a história de vida passou a ser considerada um método em voga nas ciências humanas. Percebeu-se que os valores e emoções permaneciam escondidos nos dados coletados e que a formulação de perguntas estava profundamente ligada à maneira de pensar e de sentir do pesquisador, o que transpunha para os dados de modo invisível sua própria percepção e seus preconceitos (QUEIROZ, 1991). Do ponto de vista sociológico, essa técnica mostra-se dentro da rigidez da estrutura da sociedade, a flexibilidade do comportamento humano, que não são individuais, porque são seguidos por muitos (QUEIROZ, 1991).

No contexto da metodologia qualitativa aplicada ao turismo, emprega-se a concepção trazida das Ciências Humanas, segundo a qual não se busca estudar o fenômeno em si, mas entender seu significado individual ou coletivo para a vida das pessoas. Torna-se indispensável saber o que os fenômenos socioculturais em geral representam para os sujeitos inseridos em contextos específicos. O significado tem função estruturante: em torno do que as coisas significam, as pessoas organizarão de certo modo suas vidas, incluindo as suas próprias percepções sobre a realidade em que vivem.

O pesquisador na aérea do turismo deve voltar-se para a busca do significado das coisas, porque este tem um papel organizador nos seres humanos. O que as "coisas" (fenômenos, manifestações, ocorrências, fatos, eventos, vivências, idéias, sentimentos) representam dão molde à vida das pessoas. Em outro nível, os significados que as "coisas" ganham, passam também a ser partilhados culturalmente e assim organizam o grupo social em torno destas representações e simbolismos.

\section{A Pesquisa Qualitativa em Turismo}

Em um mundo globalizado, onde a lógica homogeneizadora do mercado se impõe em escala planetária e em todas as dimensões da vida social, as pesquisas em turismo se colocam como 


\section{TURISMO EM ANÁLISE}

mais uma possibilidade de reflexão no meio acadêmico. Temas como sustentabilidade, cultura, patrimônio, religiosidade, identidade, memória, lazer, entre outros, vão sendo incorporados às atividades turísticas e ganham expressividade a partir do significado e das singularidades dos povos e grupos sociais pesquisados.

Nesse cenário, as singularidades locais passam a ser atrativos que se transformam em produtos turísticos. Lugares míticos e religiosos, a exemplo dos tradicionais centros de peregrinações - Santiago de Compostela (Espanha), Machu Pichu (Perú), Roma (Itália), Guadalupe (México), Lourdes (França), Fátima (Portugal), Aparecida (Brasil), entre outros transformam-se em destinos turísticos, diluindo fronteiras até bem pouco tempo definidas entre turistas e peregrinos, entre espaços sagrados e profanos. Às vezes, os destinos turísticos convertem-se em cenário para se explorar uma determinada cultura, transformando-a em espetáculo para os propósitos do mercado global. Outras vezes, o turismo é utilizado estrategicamente pela sociedades locais para incentivar e reforçar a autoestima e a identidade local, opondo-se às forças globais que perseguem a uniformização cultural. Tal dinâmica impulsiona as pesquisas em turismo para uma reflexão cada vez mais de cunho qualitativo posto que as particularidades, contradições e subjetividades se colocam como condição sine qua non para os estudos do turismo.

Entretanto, as pesquisas em turismo que adotam a abordagem qualitativa fundamentada na perspectiva dialética e crítica, ainda se encontram em via de construção, tanto no que diz respeito aos pressupostos teóricos quanto aos métodos e técnicas aplicadas. É comum privilegiarem a abordagem funcionalista com enfoque para a dimensão integradora e adaptativa das instituições. Ao se nortearem por funções básicas, como manutenção de padrões, integração e alcance de metas, falam de uma linguagem institucional, que explica muito mais como as instituições se mantêm, do que como se transformam. Ou seja, a atividade econômica como fonte de empregos é o principal foco.

Sem negar a importância das pesquisas em turismo fundamentadas em aportes teóricos sócioantropológicos, a exemplo dos estudos de Valene Smith (1993, 1992); MacCannell (2003); Jost Krippendorf (2009); Dennison Nash (1996); John Urry (1996, 1997); Oliveira (2004); Steil (2002, 2003); Dias (2003), que privilegiam as análises qualitativas para analisar os 


\section{TURISMO EM ANÁLISE}

aspectos culturais, políticos, econômicos e sociais dos contextos pesquisados, reforço a advertência que Margarida Barreto (2006, p. 12) faz ao afirmar que, no campo do turismo, o diálogo entre o fazer e refletir ainda "encontra-se pendente", visto que "no presente estágio da produção do conhecimento da área antropológica a respeito do turismo, (...) ainda não parece haver um corpo suficiente de comparações para que nosso trabalho possa ser classificado propriamente de antropologia aplicada”.

Todavia, não se pode deixar de registrar as inúmeras discussões que trabalham temas tão caros às ciências sociais, como sustentabilidade, políticas públicas, patrimônio, cultura, identidade, entre outros e que assumem um lugar de destaque nas pesquisas de turismo. Questões essas que se constituem como uma resposta à dinâmica da globalização e dos modos de vida de determinados grupos cujos indivíduos, ante o temor da perda de suas raízes culturais, produzidas pelas aceleradas mudanças, se refugiam cada dia mais naquilo que consideram autêntico e portadores de significados: a natureza, as crenças, as tradições e os costumes. Ou seja, tudo aquilo que se vincula ao lugar e às práticas comunitárias em que a dinâmica de afirmação das identidades atua como instrumento de coesão e reconhecimento dos diferentes povos, em que o outro passa a ser o turista, o hóspede, as populações indígenas, os visitantes ou anfitriões (SANTANA, 2009, p.21).

Paradoxalmente, o mercado global revaloriza o particular, o local e o transforma em produtos pasteurizados para o consumo dos mercados turísticos. Nessa perspectiva, as pesquisas em turismo que adotam as abordagens qualitativas são levadas a tomar uma posição crítica e reflexiva, a fim de desempenhar um papel relevante frente às imposições de um mercado turístico que atingem de forma indistinta todos os locais e destinos turísticos, sejam eles: ecológico, de aventura, cultural, religioso, pedagógico, sexual, entre outras segmentações que emergem e passam a se institucionalizar no campo dos estudos em turismo.

Desse modo, as pesquisas qualitativas em turismo tendem a contribuir tanto para um exercício reflexivo de novos conhecimentos quanto para a sua aplicabilidade nas diversas esferas do social. Ao problematizar os condicionamentos sócio-culturais de um determinado local, os pesquisadores lidam com metodologias que lhes possibilitam refletir sobre diferentes concepções da realidade. Com caráter interdisciplinar, lançam mão de diferentes abordagens 


\section{TURISMO EM ANÁLISE}

teóricas e imprimem significados diversos conforme a tradição em que se inserem. Com isso, torna o campo e a produção acadêmica do turismo um objeto de investigação atual e instigante, na medida em que possibilita a criação de um habitus disciplinar com significados diferentes (e em disputa) no momento em que evidencia a porosidade das fronteiras entre as ciências sociais humanas e naturais.

Em se tratando do conhecimento do turismo, significa trabalhar com atores e sujeitos sociais inseridos no processo de produção e não apenas no produto transmitido sob forma de narração para aquele que apre(e)nde; este deve ser visto como aquele que, em suas relações sociais, é capaz de construir novos conhecimentos. É trabalhar com os sujeitos inseridos nas diversas esferas do social de forma que eles entendam, vivenciem e participem do processo de conhecimento.

No caso das pesquisas qualitativas em turismo, necessário se faz pensar a interdisciplinaridade voltada para o problema teórico-metodológico, tanto no que se refere às questões da ciência, propriamente dita, quanto no que diz respeito aos métodos e técnicas relativos a essa abordagem que envolve diversas disciplinas. Para Japiassu, a metodologia não tem um fim em si mesma. Ela é apenas um meio que nos possibilita atingir um determinado objetivo cognitivo. Ainda, segundo o autor, a interdisciplinaridade surge como sendo a axiomática comum a um grupo de disciplinas conexas e definidas no nível hierárquico imediatamente superior, introduzindo, assim, a noção de finalidade (JAPIASSU, 1985). Por conseguinte, cabe aos pesquisadores observar que a síntese interdisciplinar somente pode tonar-se possível, tendo como base os diversos campos do conhecimento, ou seja, as disciplinas e os sujeitos que conhecem em profundidade o objeto de estudo de cada uma delas.

Esse parece ser o desafio da interdisciplinaridade do turismo. Isto é, colocar o pesquisador sempre em situação de incerteza, devendo ficar atento ao rigor dos conceitos teóricos e à procura de respostas para a problemática por ele formulada. Entender a complexidade do real, por estar em uma sociedade cada vez mais diversa e pluralista, significa levar em consideração as dúvidas, as incertezas e os erros que aparecem pelo caminho, sobretudo em relação às questões teórico-metodológicas e aos objetos investigados. 


\section{TURISMO EM ANÁLISE}

Finalizo, reiterando a ideia de que pesquisar é um ato abrangente e complexo. Não é

simplesmente observar, experimentar, fazer cálculos, entrevistar ou mesmo compilar dados. É preciso saber problematizar uma determinada realidade, observá-la e reconhecer os diversos fatores que possam influenciar na ocorrência do fenômeno, assim como no estabelecimento das possíveis interações entre eles. Quando se trata de método qualitativo, é preciso saber utilizar os procedimentos adequados que possibilitem a interpretação do fenômeno estudado a partir das informações obtidas.

\section{Referências}

BOURDIEU, Pierre. A profissão de sociólogo. Petrópolis: Vozes, 1999.

BARRETO, M. Turismo e legado cultural: as possibilidades do planejamento. Campinas, São Paulo: Papirus, 2000.

BARRETO, M. Cultura e turismo: discussões contemporâneas. Campinas, São Paulo: Papirus, 2007.

BARRETO, M. (orgs.). Turismo e identidade local: uma visão antropológica. $5^{\text {a }}$ Ed. Campinas, SP: Papirus, 2006.

BARRETO, M. "O imprescindível aporte das ciências sociais para o planejamento e a compreensão do turismo". In: Horizontes Antropológicos. Porto Alegre, ano 09, n.20, outubro de 2003, p. 15-29.

CONDORCET. Esboço de um quadro histórico dos progressos do espírito humano. Campinas/SP: Editora da UNICAMP, 1993.

COMTE, A. Curso de filosofia positiva. São Paulo: Abril Cultural, 2000. (Col. Os Pensadores).

DEMO, Pedro. Avaliação qualitativa. São Paulo: Cortez, 1991.

DURKHEIM, E. As regras do método sociológico. São Paulo: Ed. Nacional, 1977.

FLICK, Uwe. Introdução à pesquisa qualitativa. 3.ed Porto Alegre: Artemed, 2009.

JAPIASSU, H. Introdução ao pensamento epistemológico. Rio de Janeiro: Francisco Alves, 1988.

JAPIASSU, H. A revolução cientifica moderna. Rio de Janeiro: Imago, 1985.

GIL, Antonio Carlos. Métodos e técnicas de pesquisa social. São Paulo: Atlas, 1999.

GOODE, W. J.; HATT, P. K. Métodos em pesquisa social. São Paulo: Editora Nacional, 1979.

KRIPPENDORF, J. Sociologia do turismo: para uma compreensão do lazer e das viagens. 3 ed. São Paulo: Aleph, 2009.

KOSIK, Karel. Dialética do concreto. Rio de Janeiro: Paz e Terra, 1976.

LAKATOS, Eva Maria; MARCONI, Marina de Andrade. Fundamentos de metodologia científica. São Paulo: Atlas, 1993. 


\section{TURISMO EM ANÁLISE}

LOWY, Michael. Ideologias e ciência social: elementos para uma análise marxista. São Paulo: Cortez, 2002.

MACCANNELL, Dean. El turista: una nueva teoría de la clase ociosa. Barcelona: Melusina, 2003.

MARX, Karl. Manuscritos econômico-filosóficos. São Paulo: Martin Claret, 2002. (Col. A obra prima de cada autor).

MARX, Karl. Para a crítica da economia política do capital: o rendimento e suas fontes. São Paulo: Nova Cultural, 2000. (Col. Os Pensadores).

MELLUCI, Alberto. Por uma sociologia reflexiva: pesquisa qualitativa e cultura. Petrópolis, RJ: Vozes, 2005.

MINAYO, Maria Cecília de Souza. Pesquisa social: teoria, método e criatividade. Petrópolis: Vozes, 2004.

MINAYO, Maria Cecília de Souza. O desafio do conhecimento. São Paulo: Hucitec, 1996.

OLIVEIRA, Christian Dennis Monteiro de. Turismo Religioso. São Paulo: Aleph, 2004.

SANTANA, Agustín. Antropologia do turismo: analogias, encontros e relações. São Paulo: Aleph, 2009.

SMITH, V. Anfitriones e invitados. Antropología del Turismo. Madrid: Endymion. 1992.

SMITH, V. Host and guest: the anthropology of tourism. University of Pennsylvania Press,1993.

SMITH, V. Tourism alternatives: potentials and problems in the development of tourism. University of Pennsylvania Press, 1992.

STEIL, Carlos. O turismo como objeto de estudo no campo das ciências sociais. In: RIEDL, M.; ALMEIDA, J.A. e VIANA, A.L.B. (orgs) Turismo rural: tendências e sustentabilidade. Santa Cruz do Sul: Edunisc, 2002.

STEIL, Carlos. Peregrinação, romaria e turismo religioso: raízes, etimologias e interpretações antropológicas. IN: ABUMANSSUR, Edin Sued (org), Turismo Religioso: ensaios antropológicos sobre religião e Turismo. São Paulo: Papirus, 2003.

TAYLOR, S. J. \& BOGDAN, R. Introducción a los métodos cualitativos de investigación: la búsqueda de significados. Barcelona: Paidós, 1992.

THIOLLENT, M. Pesquisa-ação nas organizações. São Paulo: Ed. Atlas, 1997.

URRY, John. O olhar do turista: lazer e viagem nas sociedades contemporâneas. São Paulo: Studio Nobel/SESC, 1996.

URRY, John. Touring cultures: transformations of travel and theory. Routledge, 1997.

WEBER, M. Conceitos básicos de sociologia. São Paulo: Moraes, 1987.

WEBER, M. Sobre a Teoria das Ciências Sociais. São Paulo: Moraes, 1991.

\section{Recebido em: 26/08/2011}

Aprovado em: 07/10/2011 